\title{
Outcome of Varicocelectomy with Different Degrees of Clinical Varicocele in Infertile Male
}

\author{
S. V. Krishna Reddy, ${ }^{1}$ Ahammad Basha Shaik, ${ }^{2}$ \\ S. Sailaja, ${ }^{3}$ and $M$. Venkataramanaiah ${ }^{2}$ \\ ${ }^{1}$ Department of Urology, Narayana Medical College \& Hospital, Nellore, Andhra Pradesh 524003, India \\ ${ }^{2}$ Department of Statistics, Sri Venkateswara University, Tirupati, Andhra Pradesh 517502, India \\ ${ }^{3}$ Department of Obstetrics \& Gynaecology, Narayana Medical College, Nellore, Andhra Pradesh 524003, India
}

Correspondence should be addressed to S. V. Krishna Reddy; vijaya.nel@gmail.com

Received 22 September 2014; Revised 26 November 2014; Accepted 27 November 2014

Academic Editor: Gaffari Türk

Copyright (C) 2015 S. V. Krishna Reddy et al. This is an open access article distributed under the Creative Commons Attribution License, which permits unrestricted use, distribution, and reproduction in any medium, provided the original work is properly cited.

\begin{abstract}
Aim. To evaluate the prevalence and effect of varicocele repair on sperm motility, sperm concentration, testicular volume, and pregnancy rate in different degrees of clinical varicocele. Material and Methods. The case records were retrospectively evaluated for 482 infertile patients with varicocele who underwent varicocelectomy from December 2008 to December 2013. Semen analysis of patient at preoperative and 3-, 6-, and 12-month postoperative period was done. Varicocele was graded as per the World Health Organization grading (WHO 1993) system and included in the study. Testicular volume was noted by ultrasonography in pre- and postoperative period in one-year follow-up. Pregnancy rate was calculated at 3, 6, and 12 months of follow-up. Results. Significant differences were seen in sperm motility and concentration of patients with Grade 3 varicocele as compared with Grade 1 and Grade 2 varicocele. Significant increase in testicular volume was present after one year in Grade 3 varicocele in the postoperative period. There was significant correlation between the testicular volume and the sperm concentration. Percentage of spontaneous pregnancy in 1 year after varicocele treatment was 32 to $41 \%$ of cases. Conclusion. Varicocelectomy significantly improved sperm motility, concentration, and testicular volume. There were 32 to $41 \%$ of infertile patients who achieved pregnancy spontaneously.
\end{abstract}

\section{Introduction}

Infertility is considered as one of the main public health issues, as it affects about $15 \%$ of the couples in their reproductive age [1]. The male factor is involved in $40 \%-50 \%$ of infertility cases [2]. The most common type of male infertility is idiopathic infertility, which is characterized by the presence of one or more abnormal semen parameters with no identifiable cause [3]. Another common cause of male infertility is varicocele. While varicocele has an incidence of $4.4 \%-22.6 \%$ in general population, $21 \%-41 \%$ of men with primary infertility and $75 \%-81 \%$ of those with secondary infertility have this condition $[4,5]$. The surgical treatment is varicocelectomy which involves ligation of testicular veins. Access to the veins can be gained through subinguinal, transinguinal, or suprainguinal incision. This operation can be done by open, laparoscopic, microscopic, or embolization unilaterally or bilaterally $[6,7]$. Earlier studies on the use of varicocelectomy for the treatment of varicocele induced infertility indicated a remarkable improvement in fertility profile [8]. In addition, clinical trials concerning treatment effectiveness show conflicting results and varicocelectomy has been criticized especially under the light of evidencebased medicine (EBM). The introduction of intracytoplasmic sperm injection (ICSI) as an effective method of assisted reproduction in cases of male infertility has questioned the methods used until now [9]. Therefore, varicocele still remains one of the most controversial issues and a focus of intense debate for nearly 50 years.

The objectives of this study were to analyze, based on the clinical grade, the testicular volume, sperm motility, and sperm concentration parameters in men with varicocele and 
evaluate the changes in testicular volume and its correlation with the sperm concentration and the spontaneous pregnancy rates after varicocelectomy.

\section{Materials and Methods}

The records of 828 patients were retrospectively evaluated for infertility. 482 (58.3\%) patients with varicocele who underwent varicocelectomy at our hospital from December 2008 to December 2013 were included in this study. 336 (41.7\%) patients did not meet the inclusion criteria. The study was approved by the institutional ethics committee. All patients provided informed consent. Preoperative evaluation included a complete history, physical examination, and semen analysis. The couples with infertility history of minimum one year were included in the study. The female partner was evaluated separately by our institutional obstetrician and gynaecologist and all necessary investigation which included hormonal evaluation, ovulation studies, hysterosalpingography, and video laparoscopies was performed when necessary and those couples whose female partner was found to be normal were included in this study. Studied parameters included age of male and female partner, type and duration of infertility, testicular volume, side and grade of varicocele, side of varicocelectomy, and time since operation. The varicocele diagnosis was assigned according to the World Health Organization grading (WHO 1993). Grade 1 is a distinct dilatation of internal spermatic veins palpable during Valsalva maneuver when upright. Grade 2 is a palpable vein when upright with no Valsalva maneuver. Grade 3 is a vein both palpable and visible through the scrotal skin when upright with no Valsalva maneuver. The presence of varicocele was diagnosed by physical examination in a temperature controlled room at over $23^{\circ} \mathrm{C}$ under adequate illumination. Scrotal ultrasonography with high frequency broadband linear transducer (7.5$10 \mathrm{MHz}$ ) was used for testicular volume estimation. The scrotum and its contents are scanned in three planes, along longitudinal, axial, and transverse axis. Measurements are taken in these planes. Testicular volume measurements used ultrasonographic formula: L X W X HX 0.71, which is reported as the most accurate method, in male infertility practice [10]. Approximately 6, 9, and 12 months after varicocelectomy, testicular volumes were again examined and recorded. In all patients, preoperative semen analysis was performed using two different semen specimens, each obtained by masturbation and at least 3 weeks preoperatively and 3, 6, and 12 months after varicocele treatment according to the World Health Organization recommendation (2010). Specifically the abstinence period was 2-3 days in all cases. The interval between the two sample collections had to be more than 7 days or less than 3 weeks. Semen analysis was performed manually and included measurement of the volume of ejaculate and determination of sperm concentration, motility, and morphology according to the World Health Organization criteria [1]. Sperm concentration less than or equal to $20\left(10^{6} / \mathrm{mL}\right)$, sperm motility at first hour less than or equal to $50 \%$, and normal sperm morphology less than or equal to $30 \%$ were considered abnormal. Serum levels of $\mathrm{FSH}$, luteinizing hormone (LH), prolactin, and testosterone were also evaluated. Only patients with normal hormonal values were included in the study. All patients underwent open high retroperitoneal ligation with minor modification in the form of optical loupe magnifications. The spontaneous pregnancy rate was calculated at 3, 6, and 12 months after varicocelectomy.

2.1. Exclusion Criteria. We excluded patients who were above 40 years of age, patients with subclinical varicocele, and patients with normal semen analysis and idiopathic nonobstructive azoospermia (INOA). The diagnosis of INOA was considered in men with decreased testicular volume $\left(<15 \mathrm{~cm}^{3}\right)$, high follicle stimulating hormone (FSH) and azoospermia, or oligoasthenoteratozoospermia (OAT). In those cases, varicocele was considered a coincidental finding rather than cause of infertility.

2.2. Statistical Analysis. The results are represented as mean \pm standard deviation (SD) for continuous variables and number and percentage for categorical variables. For continuous variables, to test the difference between the three groups, ANOVA test with post hoc test was used. For categorical variables, to test the association between the groups chisquare test was used for statistical analysis. All computations were performed using the SAS 9.2 (SAS Institute Inc., Cary, NC, USA). A $P$ value of less than 0.05 was considered as statistically significant.

\section{Results}

The median age of patients in male and female was $30.4 \pm 6.9$ years and $28 \pm 4.8$ years, respectively. The average duration of infertility history was $2.8 \pm 1.22$ years. $378(78.43 \%)$ patients had primary infertility, whereas $104(21.57 \%)$ of patients had secondary infertility. Grade 1 varicocele was present in 151 (31.32\%) patients. Grade 2 varicocele was present in 212 (43.98\%) patients and Grade 3 varicocele was present in 119 $(24.68 \%)$ patients. The varicocele was located on the right side in $51(10.5 \%)$ cases, on the left side in 412 (85.5\%), and bilaterally in 19 (3.9\%). The median value of the percentage of motile sperm was 30.12, 28.8, and 19.53 in patients with Grade 1, Grade 2, and Grade 3 varicocele, respectively (Table 2). Statistical analysis shows that the progressive sperm motility difference in patients with Grade 1 and Grade 2 varicocele was not significant, but difference between patients with Grade 3 and with Grade 1 and Grade 2 varicocele was significant $(P<0.05)$. Median sperm concentration was $16.18,14.45$, and 9.48 in patients with Grade 1, Grade 2, and Grade 3 varicocele, respectively. Statistical analysis shows that sperm concentration in patient with Grade 3 varicocele was significantly low as compared to Grade 1 and Grade 2 varicocele. The sperm concentration in two groups of Grade 1 and Grade 2 had no difference. There was increase in sperm motility after 3-12 months of follow-up from $30.12 \pm 1.6$ to $55.15 \pm 1.8$ in patients who underwent Grade 1 varicocelectomy and from $28.8 \pm 1.32$ to $51.31 \pm 0.09$ in patients who underwent varicocelectomy for Grade 2 varicocele and from $19.53 \pm 1.4$ to $47 \pm 0.12$ in patients who underwent varicocelectomy for Grade 3 
varicocele after 1 year of follow-up (Table 1). There was also increase in sperm concentration after 3-12 months of followup in patients who underwent varicocelectomy for Grade 1 varicocele form $16.18 \pm 3.25$ to $40.14 \pm 1.86$ and in patients who underwent varicocelectomy for Grade 2 varicocele from $14.45 \pm 1.25$ to $31.63 \pm 1.69$ and in patients who underwent varicocelectomy for Grade 3 varicocele from $9.48 \pm 2.28$ to $18.12 \pm 3.48$. Statistical analysis showed that the improvement of both sperm motility and sperm concentration was more in patients who underwent varicocelectomy for Grade 3, rather than in patients who underwent varicocelectomy for Grade 1 and Grade 2 which was statistically significant $(P>$ $0.05)$. Significant difference was seen in 6 and 12 months compared to 3 months after varicocelectomy $(P<0.05)$. The difference between 6 and 12 months after surgery was not significant $(P>0.05)$. There was significant improvement in testicular volume after 9 months in patients who underwent varicocelectomy for Grade 3 as compared to patients who underwent varicocelectomy for Grade 1 and Grade 2 after 1 year of follow-up which was statistically significant $(P>$ 0.05 ) (Table 2). The critical mean testicular volume necessary for adequate sperm concentration was $18-20 \mathrm{~mL}$, at which spermatogenesis was at its peak (Figure 1). Percentage of spontaneous pregnancy was more after 6 months of surgery and the percentage of pregnancy rates was more in lesser grades of varicocele (Table 3 ).

\section{Discussion}

Varicocele affects the fertility and is one of the most common known causes of infertility [1]. A varicocele is abnormal dilatation and tortuosity of veins of the pampiniform plexus that drain the testis. It is more common on the left than on the right because left testicular vein enters the left renal vein at right angle, whereas right testicular vein drains into inferior vena cava. Recent laboratory work has demonstrated that there are various changes that occur at molecular level due to the effect of varicoceles. Over the last decade, research into the pathophysiology of varicoceles has focused on the following areas. These are oxidative stress-related damage, tissue hypoxia, and hormonal imbalances. There is an increasing interest in the role of reactive oxygen species (ROS) and oxidative stress in the causation of male infertility [11]. Research conducted during the last decade has provided growing support to the concept that oxidative stress (OS) is one of the main causes of male infertility. Reactive oxygen species may also act through induction of apoptosis [12]. Turkyilman et al. implicated that elevated nitric oxide (NO) may be another mechanism of injury in varicoceles, independent of other free radicals [13]. Furuya et al. documented a blood-testis barrier and immune regulatory proteins at the level of Sertoli cells, rete testis, and efferent ductules that provide immunological protection of sperm antigens and inhibit lymphocyte proliferation and complement mediated cell lysis [14]. Disruption of this barrier is believed to result in the production of anti-sperm antibodies. Haas Jr. et al. in their study had a prevalence of anti-sperm antibodies in the general population reported to be $0-2 \%$ [15]. There is a great deal of clinical data suggesting that varicocele exert

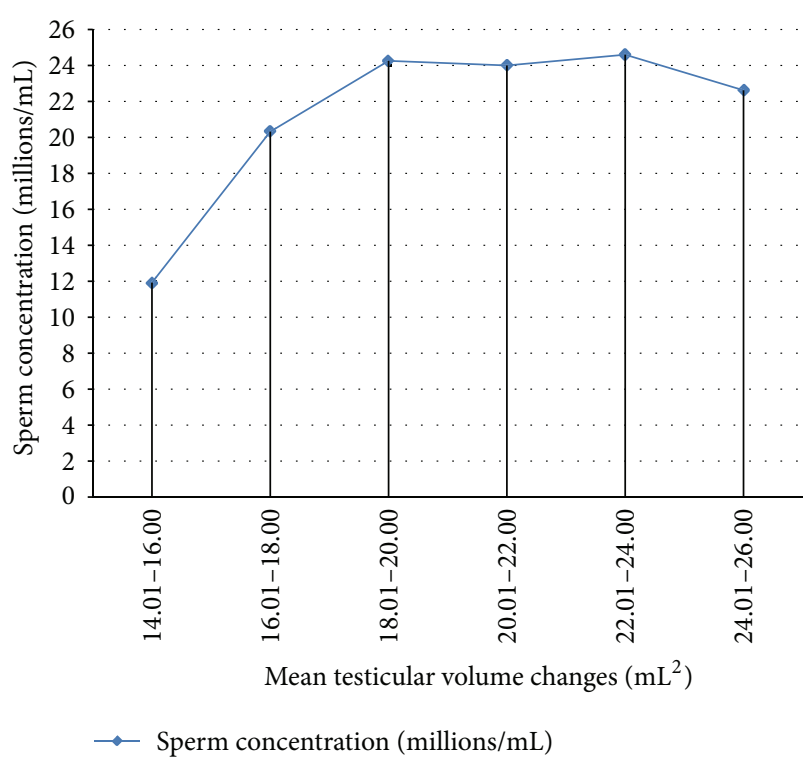

FIGURE 1: Correlation between testicular volume and sperm concentration.

a progressive deleterious effect upon male infertility, over time during adolescence.

4.1. Semen Parameter Changes. Semen analysis showed that increased number of pathologic forms, decreased progressive motility, and decreased sperm density are the most common abnormalities found in men with varicocele-related infertility. Zini et al. demonstrated that varicocele is associated with impaired disposal of residual sperm cytoplasm in the testis and epididymis [16]. The retained sperm cytoplasm causes release of free radicals and infertility. Varicocelectomy was shown to lower the number of sperm with retained cytoplasm [17]. Reichart et al. in their study concluded that varicocele may cause deleterious alterations in early spermatid head differentiation during spermiogenesis and that varicocele patients with a high incidence of sperm acrosome and nucleus malformations are appropriate candidates for varicocele correction [18]. By applying strict morphologic criteria to semen analysis, it was shown that varicocele repair improves the morphologic abnormalities of the sperm head found on preoperative semen analysis [19]. Because there is good correlation among sperm morphology, fertility index, and results from artificial reproductive techniques (ART), it is prudent to offer varicocelectomy to men with abnormal sperm morphology even with normal testicular size [20].

Unfortunately, there are few data on effect of varicoceles and varicocele repair upon semen parameters in adolescent age group. Despite these impediments, Okuyama et al. have assessed semen parameters in a group of adolescents with varicoceles who were followed up prospectively [21, 22]. Significant semen improvement was observed in both studies while Okuyama et al. noted a progressive decline of semen parameters in the untreated group. The question remains whether or not varicoceles exert a progressive deleterious effect during adulthood. The evidence that has been used to 


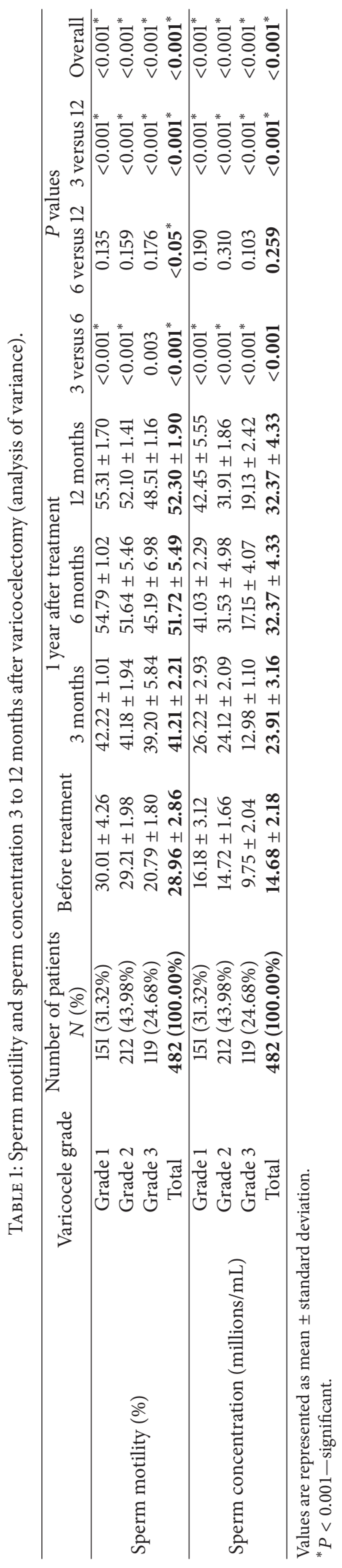




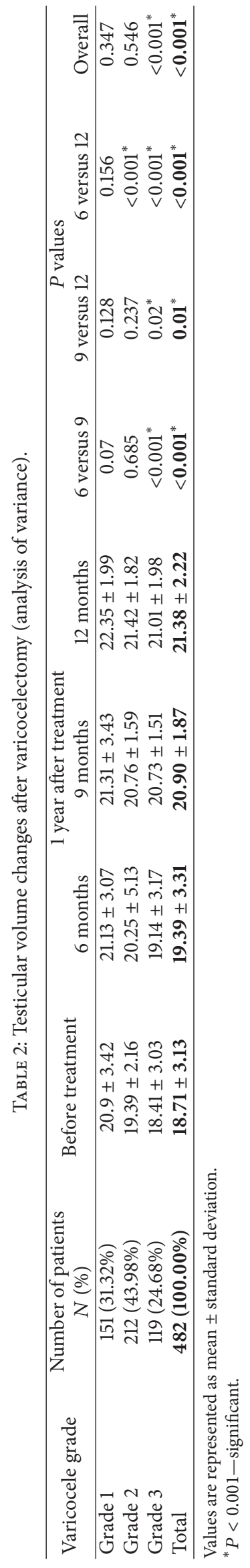


TABLE 3: Percentage of spontaneous pregnancies 3-12 months after varicocelectomy (chi-square test).

\begin{tabular}{|c|c|c|c|c|c|c|}
\hline \multirow{2}{*}{ Varicocele grade } & \multirow{2}{*}{$\begin{array}{c}\text { Number of patients } \\
\qquad N(\%)\end{array}$} & \multicolumn{4}{|c|}{ Months } & \multirow{2}{*}{$P$ value } \\
\hline & & 3 months & 6 months & 12 months & Total & \\
\hline Grade 1 & $151(31.32 \%)$ & $12(7.9 \%)$ & $19(12.5 \%)$ & $30(19.8 \%)$ & $61(41.18 \%)$ & \\
\hline Grade 2 & $212(43.98 \%)$ & $16(7.5 \%)$ & $25(12.79 \%)$ & $48(22.6 \%)$ & $89(40.29 \%)$ & $>0.05$ \\
\hline Grade 3 & $119(24.68 \%)$ & $9(7.5 \%)$ & $12(10.1 \%)$ & $18(15.1 \%)$ & $39(32.77 \%)$ & \\
\hline Total & $482(100.00 \%)$ & $37(7.67 \%)$ & $56(11.61 \%)$ & $96(19.91 \%)$ & $189(39.21 \%)$ & \\
\hline
\end{tabular}

Values are represented as number (\%).

$P>0.05-$ not significant.

support this hypothesis is increased prevalence of varicoceles amongst men with secondary infertility as compared to men with primary infertility $[23,24]$. The increased prevalence of varicocele amongst men with secondary infertility suggests that this vascular lesion has a progressive rather than static effect upon male infertility.

4.2. Testicular Volume Changes. Testicular volume during preadolescence is constant, and at the onset of puberty the testis suddenly increases in size even prior to other pubertal changes. In adolescents with varicocele, the rapid growth of the testis between the ages of 11 and 16 is affected by varicocele and results in a volume discrepancy between the right and left testis. The hypothesis that there is a negative correlation between testicular volume and sperm density, motility, and number of pathologic forms is well supported in the literature $[25,26]$. Significant volume loss in adolescents with varicocele has been noted in $77 \%$ of boys, $10 \%$ of whom had a left testis one-fourth of the size of the right testis [27]. Testicular hypotrophy is time-dependent [28].

4.3. Histopathology. Testicular biopsy in males with varicocele shows a wide array of abnormalities. The most common findings are Leydig cells hyperplasia, decreased number of spermatogonia per tubule, spermatogenesis arrest, and sloughing of germinal epithelium [29, 30]. A thickened basement membrane of seminiferous tubules and proliferative lesions of endoepithelium are often demonstrated and may affect transport of oxygen and glucose through these structures [31]. The damage to the basement membrane seems to be time-dependent, as shown by ultrastructural and immunohistochemical observations that highlighted focal damage at the level of the peritubular basal lamina in pubertal boys with varicocele, but this damage was not as severe as that described in adult varicocele [32].

Sayfan et al. in their study have shown that testicular volume fails to either increase or actually decrease in size of testis that is associated with varicoceles [33]. The loss of testicular volume in the presence of varicocele is related to the loss of seminiferous tubule elements and decrease in tubular diameter, which may lead to higher incidence of subfertility and abnormal seminal parameters. Pinto et al. noted that varicoceles were associated with significant reduction in testicular size [20]. Right testicular volume improved more than left testicular volume to a statistically significant degree after varicocelectomy. Explanation for the improved rightsided testicular volume after left varicocelectomy may be due to the crossover of venous circulation between left and right sides [33]. It should be noted, however, that catchup testicular growth among adolescents following varicocele repair is not universal and may be dependent on several factors including patients age [22]. More recently, Condorelli also found reduced semen parameters in patients with mean testicular volume (MTV) of less than $12 \mathrm{~mL}$ [34]. It was however a retrospective study and the fertility status of the patients was not clearly defined as the average sperm density in these patients with MTV less than $12 \mathrm{~mL}$ was still $28 \times$ $106 \mathrm{~mL}^{-1}$.

Evaluation of the semen is the primary investigative tool in the assessment of male fertility. Over the last few decades, there have been reports to suggest decreased human semen quality (defined as sperm density) in the general population in whom scrotal ultrasound has also become the primary imaging modality in the evaluation of men with reduced semen quality [35]. Sikamoto in Japan in an assessment of 397 infertile patients using ultrasound reported that patients with total testicular volume (TTV) of $20 \mathrm{~mL}$ (or mean $10 \mathrm{~mL}$ ) or more had normal sperm parameters. They also reported a total testicular volume (TTV) below $15 \mathrm{~mL}$ (MTV-7.5 mL) as indicative of severe oligospermia $\left(<5 \times 106 \mathrm{~mL}^{-1}\right)$ [36]. Tijani et al. in their study reported the relationship between testicular volume and function using scrotal ultrasound scan in black West African men and testicular volume was an indicator of severity of infertility with a statistically significant relationship between the testicular volume and the sperm density [37]. A mean testicular volume (MTV) change from 16 to $14 \mathrm{~mL}$ was associated with a sharp reduction in sperm density from 11 million to 5.2 million $/ \mathrm{mL}$. In our series also total testicular volume correlated well with severity of oligospermia.

All patients in our series underwent high ligation of internal spermatic veins above the level of such crossover vessels. The results of our present study demonstrate that the repair of varicocele by surgery caused high significant improvement in progressive sperm motility, sperm concentration, and morphology and pregnancy rates (Figure 2). Testicular volume on scrotal ultrasound correlates well with severity of oligospermia in men with subfertility, while the critical mean testicular volume necessary for adequate spermatogenesis has not been determined; it appears that there is an optimal testicular volume of $18-20 \mathrm{~mL}$ at which spermatogenesis is at its peak. Testicular volume increased in our series after 9 months after varicocelectomy which was significant in Grade III varicocele. Low initial sperm count may benefit more from 


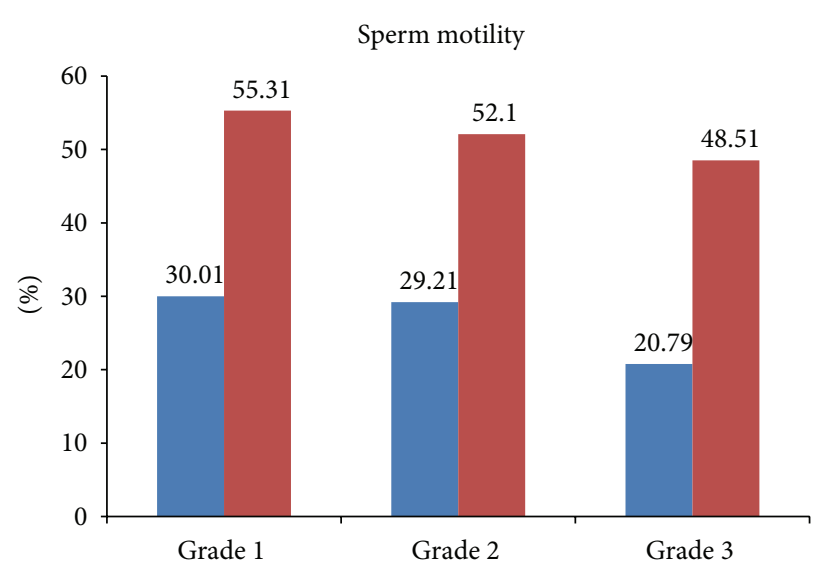

(a)

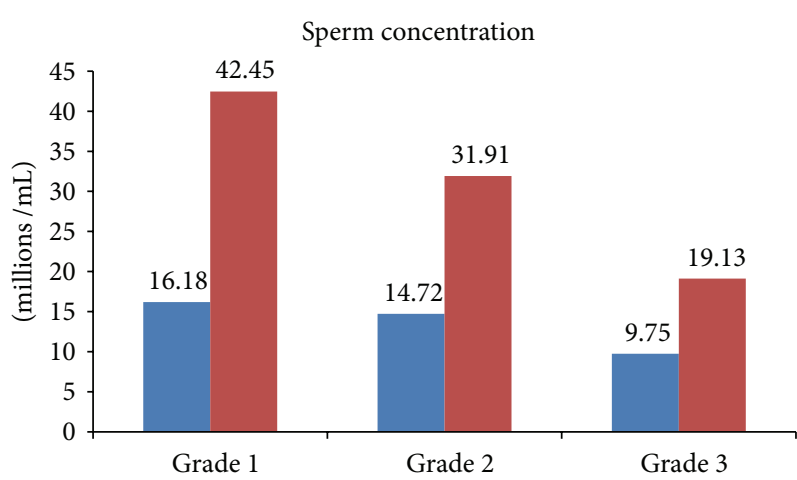

(b)

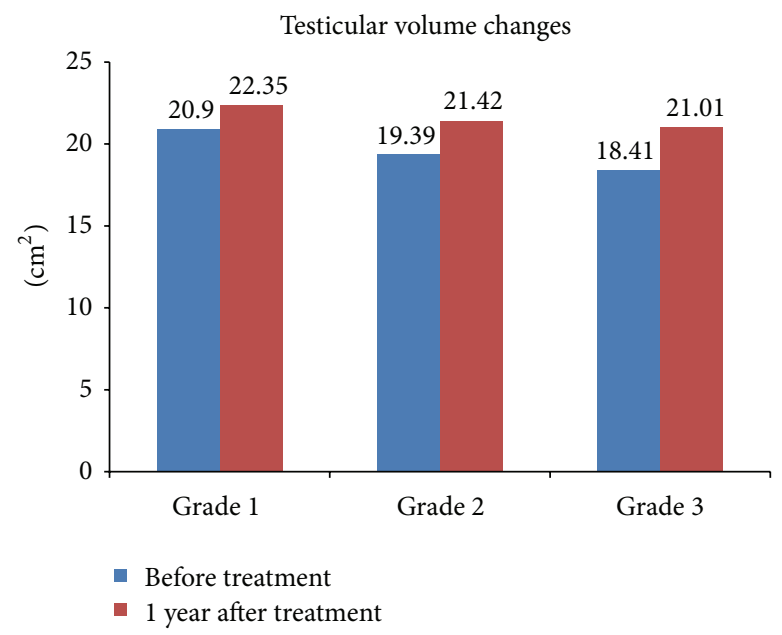

(c)

FIGURE 2: (a) Comparison of sperm motility before treatment and 1 year after treatment of varicocele. (b) Comparison of sperm concentration before treatment and 1 year after treatment of varicocele. (c) Comparison of testicular volume changes before treatment and 1 year after treatment of varicocele.

assisted reproductive techniques or varicocelectomy followed by assisted reproduction. Kamischke and Nieschlag claimed that varicocele repair had no improvement in male fertility [38]. However our data shows that the percentage of spontaneous pregnancies was $31-40 \%$. Schlegel had similar data like our study but documented reduced sperm motility and concentration in men with bilateral varicocele as compared with unilateral varicocele men [39]. In view of these issues, American Society of Reproductive Medicine and American Urological Association have suggested clear guidelines for the evaluation and management of these patients [40,41].

\section{Conclusion}

Based upon current data available several conclusions may be reached. First, there is very strong evidence to support the fact that, as observed for centuries, varicocele exerts a deleterious effect upon sperm motility, concentration, morphology, and testicular volume. Second, repair of varicocele improved all the parameters. Third, testicular volume on scrotal ultrasound correlates well with severity of oligospermia in men with subfertility and $32-41 \%$ of infertile men achieved pregnancy within one year after treatment and it also helps in downgrading the level of assisted reproductive therapy required.

\section{Conflict of Interests}

The authors declare that they have no conflict of interests.

\section{References}

[1] World Health Organization, Laboratory Manual for the Examination of Human Semen and Sperm-Cervical Mucus Interaction, Cambridge University Press, New York, NY, USA, 4th edition, 1999.

[2] L. Speroff, R. H. Glass, and N. G. Kase, "Infertility," in Clinical Gynecological Endocrinology and Infertility, pp. 201-246, Lippincott Williams \& Wilkins, Baltimore, Md, USA, 6th edition, 1999. 
[3] H. W. G. Baker, "Male infertility," Endocrinology and Metabolism Clinics of North America, vol. 23, no. 4, pp. 783-793, 1994.

[4] D. C. Saypol, "Varicocele," Journal of Andrology, vol. 2, pp. 61-71, 1981.

[5] J. I. Gorelick and M. Goldstein, "Loss of fertility in men with varicocele," Fertility and Sterility, vol. 22, pp. 469-474, 1971.

[6] A. M. Al-Kandari, H. Shabaan, H. M. Ibrahim, Y. H. Elshebiny, and A. A. Shokeir, "Comparison of outcome of different varicocelectomy techniques: open inguinal, laparoscopic, and sub inguinal microscopic varicocelectomy: a randomized clinical trial," Urology, vol. 69, no. 3, pp. 417-420, 2007.

[7] Y. Gat, G. N. Bachar, K. Everaert, U. Levinger, and M. Gornish, "Induction of spermatogenesis in azoospermic men after internal spermatic vein embolization for the treatment of varicocele," Human Reproduction, vol. 20, no. 4, pp. 1013-1017, 2005.

[8] W. S. Tulloch, "Varicocele in sub fertility: results of treatment," British Medical Journal, vol. 2, pp. 356-358, 1955.

[9] A. C. van Steirteghem, Z. Nagy, H. Joris et al., "High fertilization and implantation rates after intracytoplasmic sperm injection," Human Reproduction, vol. 8, no. 7, pp. 1061-1066, 1993.

[10] H. Sakamoto, K. Saito, M. Oohta, K. Inoue, Y. Ogawa, and H. Yoshida, "Testicular volume measurement comparison of ultra sonography, orchidometry and water displacement," Urology, vol. 69, no. 1, pp. 152-157, 2007.

[11] R. K. Sharma and A. Agarwal, "Role of reactive oxygen species in male infertility," Urology, vol. 48, no. 6, pp. 835-850, 1996.

[12] K. Cam, F. Simsek, M. Yuksel et al., "The role of reactive oxygen species and apoptosis in the pathogenesis of varicocele in a rat model and efficiency of vitamin E treatment," International Journal of Andrology, vol. 27, no. 4, pp. 228-233, 2004.

[13] Z. Turkyilman, S. Gulen, K. Sönmez et al., "Increased nitric oxide is accompanied by lipid oxidation in adolescent varicocele," International Journal of Andrology, vol. 27, no. 3, pp. 183187, 2004.

[14] S. Furuya, Y. Kumamoto, and S. Sugiyama, "Fine structure and development of Sertoli junctions in human testis," Archives of Andrology, vol. 1, no. 3, pp. 211-219, 1978.

[15] G. G. Haas Jr., D. B. Cines, and A. D. Schreiber, "Immunologic infertility: identification of patients with antisperm antibody," The New England Journal of Medicine, vol. 303, no. 13, pp. 722$727,1980$.

[16] A. Zini, G. Defreitas, M. Freeman, S. Hechter, and K. Jarvi, "Varicocele is associated with abnormal retention of cytoplasmic droplets by human spermatozoa," Fertility and Sterility, vol. 74, no. 3, pp. 461-464, 2000.

[17] A. Zini, M. Buckspan, M. Jamal, and K. Jarvi, "Effect of varicocelectomy on the abnormal retention of residual cytoplasm by human spermatozoa," Human Reproduction, vol. 14, no. 7, pp. 1791-1793, 1999.

[18] M. Reichart, F. Eltes, Y. Soffer, E. Zigenreich, L. Yogev, and B. Bartoov, "Sperm ultramorphology as a pathophysiological indicator of spermatogenesis in males suffering from varicocele," Andrologia, vol. 32, no. 3, pp. 139-145, 2000.

[19] J. Sayfan, L. Siplovich, L. Koltun, and N. Benyamin, "Varicocele treatment in pubertal boys prevents testicular growth arrest," Journal of Urology, vol. 157, no. 4, pp. 1456-1457, 1997.

[20] K. J. Pinto, R. L. Kroovand, and J. P. Jarow, "Varicocele related testicular atrophy and its predictive effect upon fertility," Journal of Urology, vol. 152, no. 2, pp. 788-790, 1994.

[21] A. Okuyama, M. Nakamura, M. Namiki et al., "Surgical repair of varicocele at puberty: preventive treatment for fertility improvement," Journal of Urology, vol. 139, no. 3, pp. 562-564, 1988.

[22] M. Yamamoto, H. Hibi, S. Katsuno, and K. Miyake, "Effect of varicocelectomy on testis volume and semen parameters in adolescents: a randomized prospective study," Nagoya Journal of Medical Science, vol. 139, pp. 562-564, 1995.

[23] J. I. Gorelick and M. Goldstein, "Loss of fertility in men with varicocele," Fertility and Sterility, vol. 59, no. 3, pp. 613-616, 1993.

[24] M. A. Witt and L. I. Lipshultz, "Varicocele: a progressive or static lesion?” Urology, vol. 42, no. 5, pp. 541-543, 1993.

[25] "The influence of varicocele on parameters of fertility in a large group of men presenting to infertility clinics. World Health Organization," Fertility and Sterility, vol. 57, no. 6, pp. 1289-1293, 1992.

[26] F. Hadziselimovic, B. Herzog, and P. Jenny, "The chance for fertility in adolescent boys after corrective surgery for varicocele," Journal of Urology, vol. 154, no. 2, pp. 731-733, 1995.

[27] R. P. Lyon, S. Marshall, and M. P. Scott, "Varicocele in childhood and adolescence: implication in adulthood infertility?" Urology, vol. 19, no. 6, pp. 641-644, 1982.

[28] L. I. Lipshultz and J. N. Corriere Jr., "Progressive testicular atrophy in the varicocele patient," Journal of Urology, vol. 117, no. 2, pp. 175-176, 1977.

[29] R. Ponchietti, G. Grechi, and G. Dini, "Varicocele in adolescents: ultrastructural aspects," Acta Europaea Fertilitatis, vol. 17, no. 1, pp. 47-50, 1986.

[30] M. Castro-Magana, M. Angulo, A. Canas, and J. Uy, "Leydig cell function in adolescent boys with varicoceles," Archives of Andrology, vol. 24, no. 1, pp. 73-79, 1990.

[31] F. Hadziselimovic, "Testicular and vascular changes in patients with varicocele," Acta Urologica Belgica, vol. 63, no. 2, pp. 51-54, 1995.

[32] G. Santoro, C. Romeo, P. Impellizzeri, C. Gentile, G. Anastasi, and A. Santoro, "Ultrastructural and immunohistochemical study of basal lamina of the testis in adolescent varicocele," Fertility and Sterility, vol. 73, no. 4, pp. 699-705, 2000.

[33] J. Sayfan, Y. G. Adam, and Y. Soffer, "A new entity in varicocele subfertility: the "cremasteric reflux"', Fertility and Sterility, vol. 33, no. 1, pp. 88-90, 1980.

[34] R. Condorelli, A. E. Calogero, and S. La Vignera, "Relationship between testicular volume and conventional or nonconventional sperm parameters," International Journal of Endocrinology, vol. 2013, Article ID 145792, 6 pages, 2013.

[35] S. J. Gordon, U. Otite, P. Maheshkumar, P. Cannon, and V. H. Nargund, "The use of scrotal ultrasonography in male infertility," BJU International, vol. 87, no. 4, pp. 417-420, 2001.

[36] H. Sakamoto, Y. Ogawa, and H. Yoshida, "Relationship between testicular volume and testicular function: comparison of the Prader orchidometric and ultrasonographic measurements in patients with infertility," Asian Journal of Andrology, vol. 10, no. 2, pp. 319-324, 2008.

[37] K. H. Tijani, B. O. Oyende, G. O. Awosanya, R. W. Ojewola, and A. O. Yusuf, "Assessment of testicular volume: a comparison of fertile and sub-fertile West African men," African Journal of Urology, vol. 20, no. 3, pp. 136-140, 2014.

[38] A. Kamischke and E. Nieschlag, "Analysis of medical treatment of male infertility," Human Reproduction, vol. 14, no. 1, pp. 1-23, 1999.

[39] P. N. Schlegel, "Is assisted reproduction the optimal treatment for varicocele- associated male infertility? A cost-effectiveness analysis," Urology, vol. 49, no. 1, pp. 83-90, 1997. 
[40] Male Infertility Best Practice Policy Committee of the American Urological Association and Practice Committee of the American Society for Reproductive Medicine, "Report on varicocele and infertility," Fertility and Sterility, vol. 82, supplement 1, pp. S142-S145, 2004.

[41] I. D. Sharlip, J. P. Jarow, A. M. Belker et al., "Best practice policies for male infertility," Fertility and Sterility, vol. 77, no. 5, pp. 873882, 2002. 


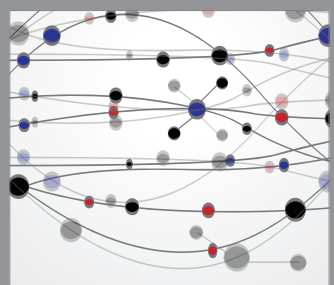

The Scientific World Journal
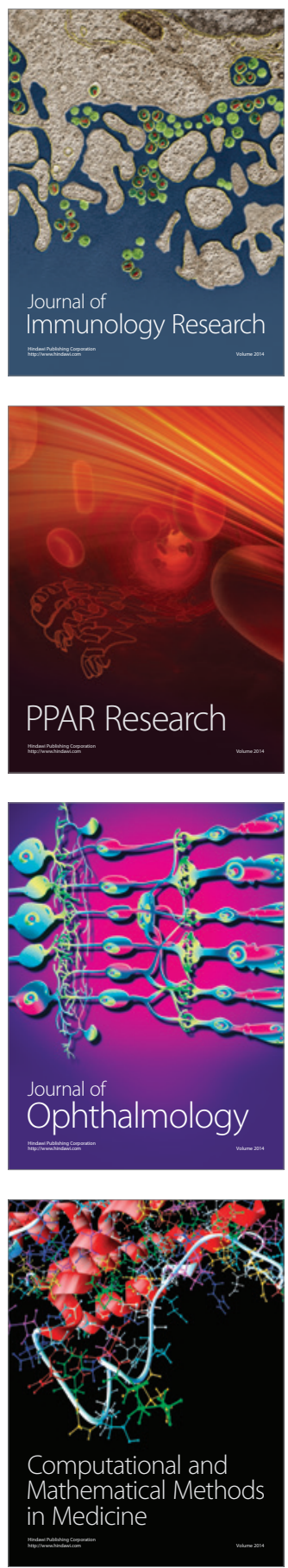

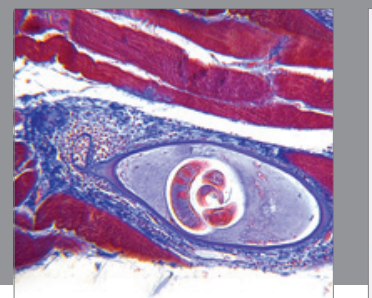

Gastroenterology

Research and Practice
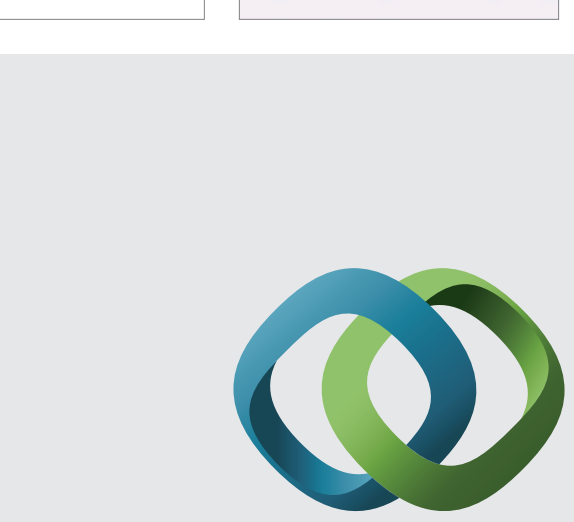

\section{Hindawi}

Submit your manuscripts at

http://www.hindawi.com
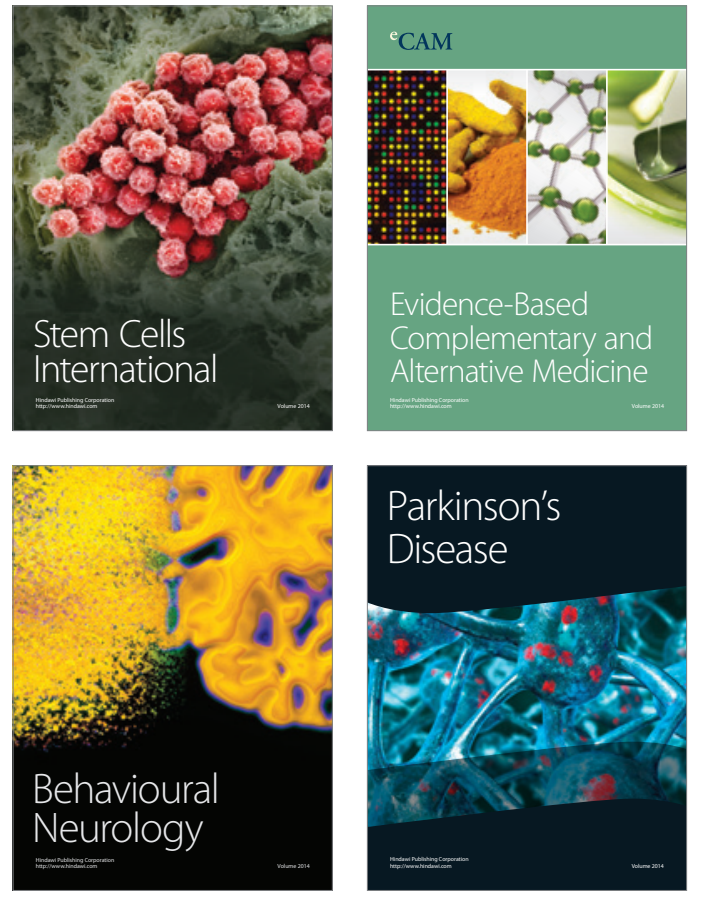
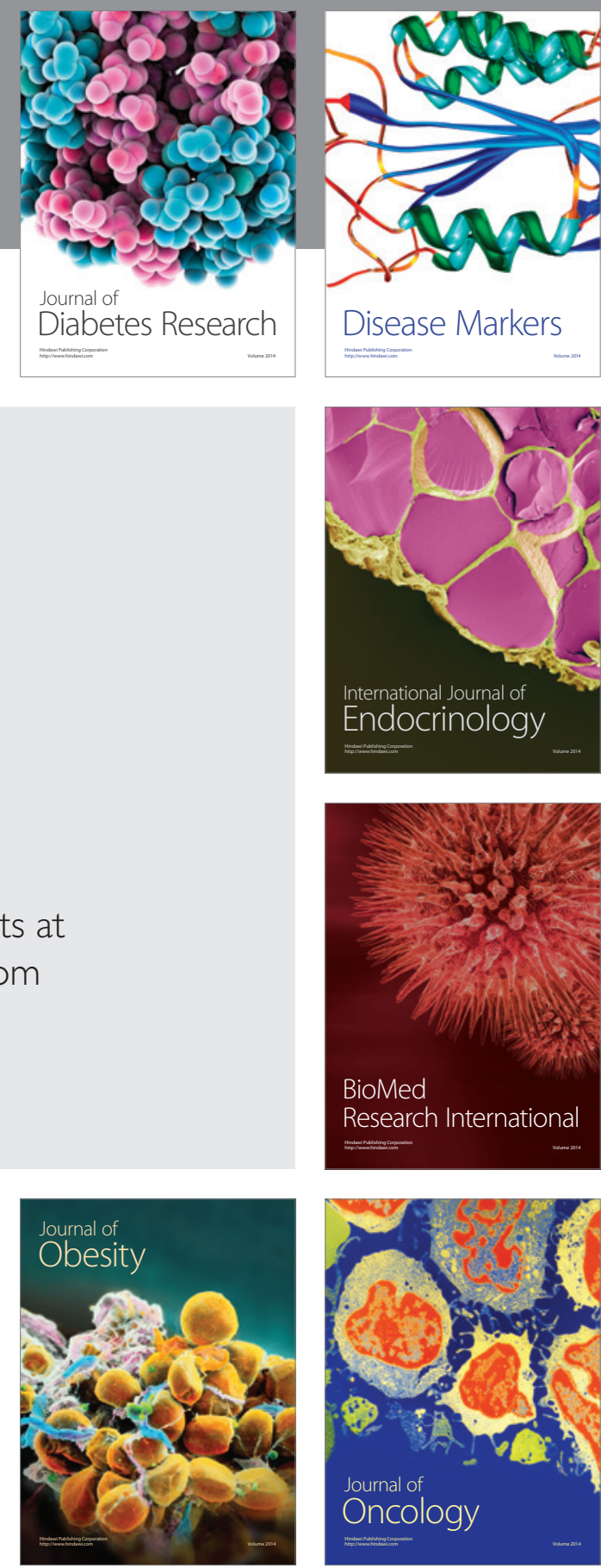

Disease Markers
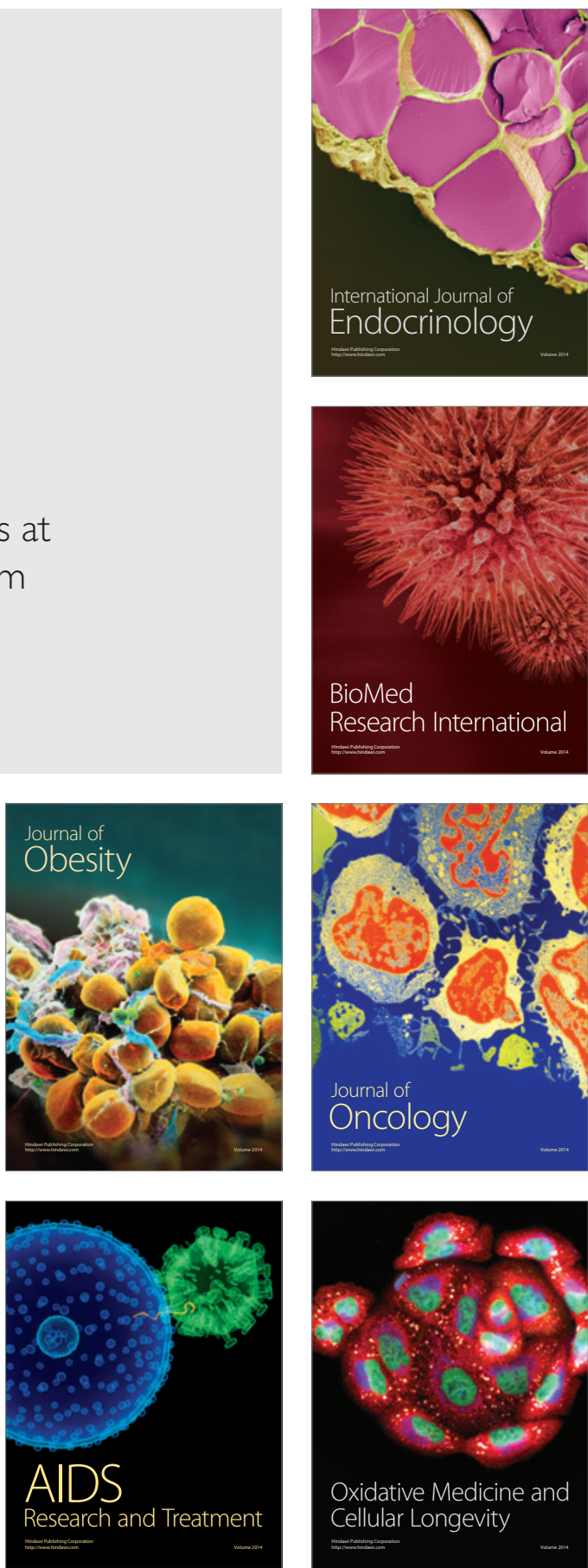